\title{
PENGARUH PENEMPATAN JARAK TITIK LAMPU DAN KOMBINASI WARNA TERHADAP PERUBAHAN KONDISI LINGKUNGAN LAPANGAN INDOOR BULUTANGKIS
}

\author{
Edi Irwanto, Moh Agung Setiabudi \\ Universitas PGRI Banyuwangi. \\ e-mail: irwantoedi88@gmail.com
}

\begin{abstract}
This research aims to measure whether there is effect of placement of the point of lights and color combinations to changes in the environmental conditions of indoor badminton court. The design of the research was experimented research. The color of light used was white, yellow and combination of both. Modified layout and placement distance is done with a combination of parallel and zig-zag, and 7, 7.5, 8, 8.5, and $9 \mathrm{~m}$ lamp height. Measurements using Thermometer, Hygrometer, and Luxmeter. The research was also conducted by field survey using questionnaire method to 5 athletes. The results of data collection will be analyzed based on the SNI 16-7063-2004 working climate criteria as well as the criteria for grouping existing data. The results showed that the placement of the point of light and color combinations affect the environmental conditions of indoor badminton field. The athlete's comfort lies in the placement of standard lighting points with one color at a height of 8 meters.
\end{abstract}

Keywords: badminton, environmental conditions, comfort.

\begin{abstract}
ABSTRAK
Penelitian ini bertujuan untuk mendapatkan pengaruh penempatan jarak titik lampu dan kombinasi warna terhadap perubahan kondisi lingkungan lapangan indoor bulutangkis. Penelitian dilakukan dengan eksperimen, enis warna cahaya lampu yang digunakan adalah putih, kuning dan kombinasi keduanya. Modifikasi tata letak dan jarak penempatan dilakukan dengan kombinasi sejajar dan zig-zag, dan ketinggian lampu 7, 7.5, 8, 8.5, dan $9 \mathrm{~m}$. Pengukuran menggunakan Thermometer, Hygrometer, dan Luxmeter. Penelitian juga dilakukan dengan cara survei lapangan menggunakan metode kuesioner terhadap 5 atlet. Hasil pengambilan data akan dianalisis berdasarkan nilai ambang batas iklim kerja SNI 167063-2004 serta kriteria pengelompokkan data yang ada. Hasil penelitian menunjukan bahwa penempatan jarak titik lampu dan kombinasi warna berpengaruh terhadap kondisi lingkungan lapangan indoor bulutangkis. Kenyamanan atlet terletak pada penempatan titik lampu standart dengan satu warna pada ketinggian lampu 8 meter.
\end{abstract}

Kata kunci: bulutangkis, kondisi lingkungan, kenyamanan.

\section{PENDAHULUAN}

Olahraga bulutangkis mulai men-

jadi salah satu olahraga yang bergengsi,

Cina dan Indonesia merupakan dua negara yang menjadi barometer kekuatan bulu-

tangkis dunia (PB PBSI, 2004). Bulu-

tangkis dapat dilakukan dalam lapangan

olahraga indoor. Lapangan olahraga 
indoor adalah sebuah bangunan yang memberikan fasilitas berupa tempat olahraga tertutup (Farid K.M \& Andi R, 2012). Lapangan olahraga indoor dituntut mampu memberi-kan pencahayaan yang ideal sesuai standart. Hal ini dimaksudkan untuk memenuhi kenyamanan visual bagi orang-orang yang beraktifitas di dalamnya. Kenyamanan visual erat kaitannya dengan penglihatan manusia. Penginderaan yang baik akan sangat membantu seseorang dalam melihat atau memvisualisasikan sebuah objek (Irfan S., 2007).

Iluminasi atau kuat pencahayaan adalah kuantitas cahaya pada level pencahayaan terhadap suatu permukaan tertentu. Kuat pencahayaan suatu ruangan ditentukan oleh jenis aktifitas yang dilakukan. Begitupula untuk pencahayaan di dalam gedung olahraga. Lapangan penglihatan, pencegahan kesilauan, arah sinar, warna dan panas penerangan terhadap keadaan ling-kungan (Agustin P.W, 2010). Standar pencahayaan untuk olahraga Bulutangkis (indoor) untuk kategori latihan adalah 200 lux dan pertandingan 400 lux (Farid K.M \& Andi R, 2012).

Temperatur yang dapat diterima sebagai zona nyaman untuk permainan bulutangkis adalah $16-1933^{\circ} \mathrm{C}$ ketika berkeringat, sedangkan suhu normal adalah $25^{\circ} \mathrm{C}$. Cara yang paling murah untuk memper-oleh kenyamanan termal adalah secara alamiah melalui pendekatan arsitektur, yaitu merancang bangunan dengan mem-pertimbangkan orientasi terhadap matahari dan arah angin, pemanfaatan elemen arsi-tektur dan material bangunan, serta peman-faatan elemen-elemen lansekap (Basaria T., 2005).

Kenyamanan termal sangat dibutuhkan tubuh atlet bulu tangkis agar konsentrasinya tetap terjaga prima. Kenyamanan tergantung pada variabel iklim (radiasi matahari, suhu udara, kelembaban udara, dan kecepatan angin). Tingkat ilumi-nasi yang dibutuhkan dalam bermain bulu-tangkis adalah: 
Tabel 1. Illuminance Level (Sumber Animous, 2015)

Illuminance Plot with luminaries at $5 \mathrm{~m}$ above floor level

\begin{tabular}{|c|c|}
\hline Average illuminance & 474 lux \\
\hline Minimum illuminance & 305 lux \\
\hline Maximum illuminance & 595 lux \\
\hline
\end{tabular}

Berdasarkan uraian latar belakang di atas maka perlu dilakukan penelitian pengaruh pengaruh penempatan jarak titik lampu dan kombinasi warna terhadap perubahan kondisi lingkungan lapangan bulu tangkis.

Bulutangkis pada umumnya dimainkan di sports halls yang merupakan ruangan yang elastis besar dengan langitlangit yang tinggi. Menurut standar BWF, lapangan bulutangkis memiliki tinggi letak lampu dari lapangan sekitar 7,5 m sampai $9 \mathrm{~m}$, dan terletak pada setiap sisi lapangan. Temperatur yang dapat diterima sebagai zona nyaman untuk permainan bulutangkis adalah $16-19^{\circ} \mathrm{C}$ ketika berkeringat. Sedang-kan suhu normal adalah $25^{\circ} \mathrm{C}$, suhu udara tingkat pertukaran udara minimal 1,5 ACH.
Luminer harus dipasang pada ketinggian 5 meter dari permukaan lapangan dan $\pm 0,9$ meter dari pinggir lapangan. Tingkat iluminasi yang dibutuhkan dalam bermain bulutangkis adalah average illuminance 474 lux, minimum illuminance 305 lux dan maximum illuminance 595 lux. Sesuai standar, skema pendekatan luminer dapat dilihat pada gambar_berikut ini.

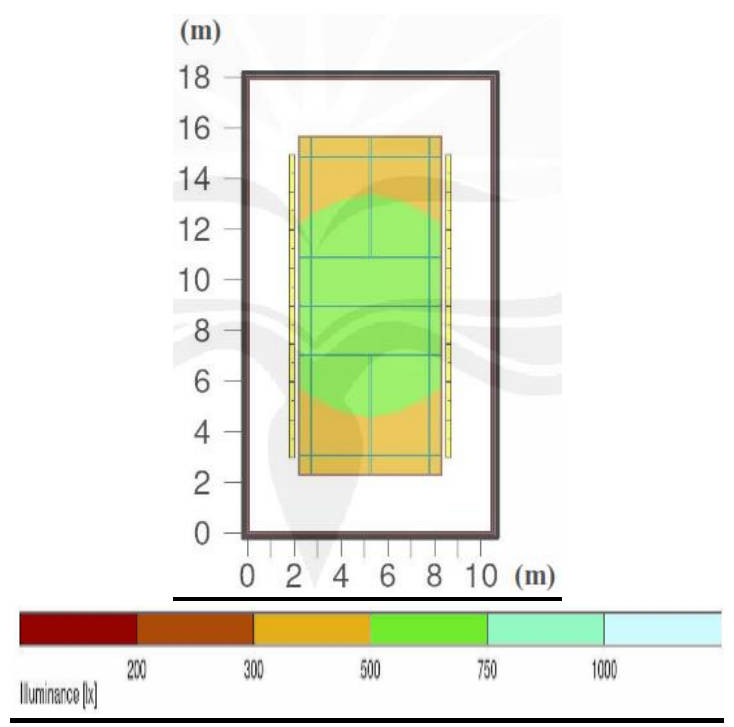

Gambar 1. Skema peletakan luminer (Animous, 2015)

Menggunakan lampu double fluorescent 2 x 80 watt di mana terdapat lensa atau diffuser yang membungkus lampu agar tidak terlalu silau. 


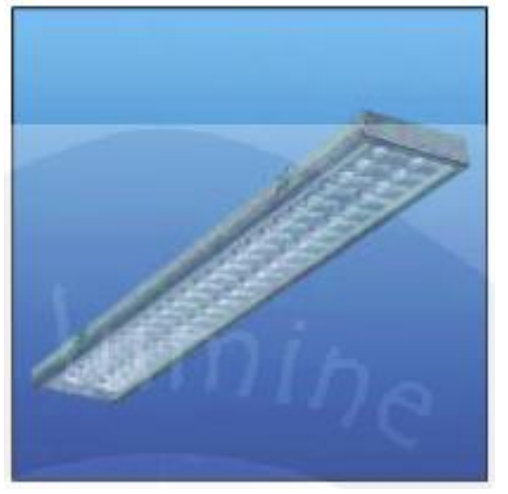

Gambar 2. Lampu fluorescent untuk lapangan bulutangkis (Animous, 2015). Warna dalam desain berperan penting karena warna dapat memberikan efek secara psikologis. Sumber cahaya putih dapat dikelompokkan dalam 3 (tiga) kelompok menurut tampak warnanya (lihat tabel 2).

Tabel 2. Tampak warna terhadap temperatur warna (Sumber SNI 03-65752001)

\begin{tabular}{|c|c|}
\hline $\begin{array}{c}\text { Temperatur warna } \\
\text { K (Kelvin) }\end{array}$ & $\begin{array}{c}\text { Tampak } \\
\text { warna }\end{array}$ \\
\hline$>5300$ & Dingin \\
\hline $3300-5300$ & Sedang \\
\hline$<3300$ & Hangat \\
\hline
\end{tabular}

Kesan umum yang berhubungan dengan tingkat pencahayaan yang bermacam-macam dan tampak warna yang berbeda dengan lampu fluoresen dapat dilihat pada tabel 3 .

Tabel 3. Hubungan tingkat pencahayaan dengan tampak warna lampu (Sumber SNI 03-6575-2001)

\begin{tabular}{|c|c|c|c|}
\hline \multirow{2}{*}{$\begin{array}{c}\text { Tingkat } \\
\text { penca- } \\
\text { hayaan } \\
(\boldsymbol{L} \boldsymbol{u} \boldsymbol{x})\end{array}$} & \multicolumn{3}{|c|}{ Tampak warna lampu } \\
\cline { 2 - 4 } & Hangat & Sedang & Dingin \\
\hline$<500$ & Nyaman & Netral & Dingin \\
\hline $500-1000$ & & & \\
\hline $1000-2000$ & Stimulasi & Nyaman & Netral \\
\hline $2000-3000$ & & & \\
\hline$>3000$ & Tdk alami & Stimulasi & Nyaman \\
\hline
\end{tabular}

Panas pada dasarnya dapat berpindah dari suatu media ke media lain. Terdapat 3 metode dasar atau proses perpindahan panas, yaitu secara konduksi, konveksi, dan radiasi. Proses penguapan uap air dari kulit (keringat) dari permukaan kulit menun-jukkan adanya proses pelepasan panas dari tubuh. Proses yang utama adalah melalui sirkulasi darah dan pengeluaran keringat. Respon otomatis pengaturan panas tubuh biasanya terjadi jika temperatur darah melebihi $98,6^{\circ} \mathrm{F}$ dan pengaturan serta pengendalian temperatur tubuh dilakukan oleh otak. Perpindahan atau keseimbangan antara panas lingkungan dengan tubuh seseorang dapat terlihat pada rumus berikut (Nurul S.V, 2008):

$$
H=M \pm R \pm C-E
$$

Keterangan: $\mathrm{H}=$ Jumlah panas tubuh 
$\mathrm{M}=$ Panas metabolic

$\mathrm{R}=$ Panas radian/infrared

$\mathrm{C}=$ Panas konveksi

$\mathrm{E}=$ Panas evaporasi

Aktivitas fisik yang mempunyai kontribusi terhadap total tekanan panas adalah aktivitas yang menyebabkan terjadinya peningkatan panas metabolik dalam tubuh sesuai dengan intensitas pekerjaan. Suhu tubuh adalah panas yang dihasilkan dari sistem organ seperti otak, jantung, paru-paru dan saluran pencernaan. Suhu tubuh (core temperature) berkisar antara $99-100^{\circ} \mathrm{F}\left(37-38^{\circ} \mathrm{C}\right)$.

Volume keringat lebih dari 5 liter akan mengindikasikan adanya pajanan tekanan panas yang dapat menyebabkan dehidrasi dan harus dikendalikan. Jika terjadi pajanan selama 2-4 jam, maka volume keringat tidak boleh lebih dari 1 liter per jam.

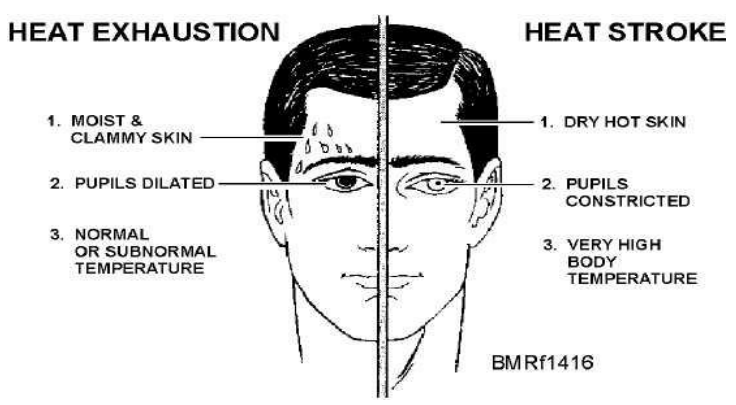

Gambar 3. Tanda dan gejala heat stroke dan heat exhaustion

(Nurul S.V, 2008)
Bila dilihat dari rumus keseimbang-an panas $[\mathrm{H}=(\mathrm{M}-\mathrm{W}) \pm \mathrm{C} \pm \mathrm{R}$ - E], total tekanan panas dapat diturunkan dengan melakukan modifikasi satu atau lebih faktor yang mempengaruhi seperti panas metabo-lisme yang dihasilkan, perpindahan panas melalui konveksi, radiasi, atau melalui evaporasi. Tingkat panas lingkungan $(C, R$, dan $E)$ dapat dikendalikan melalui pengen-dalian enjiniring seperti ventilasi, AC, dan perubahan pada proses.

\section{METODE PENELITIAN}

Penelitian dilakukan dengan eksperimen di laboratorium dengan membuat peralatan uji. Penelitian dilakukan di sport hall Universitas PGRI Banyuwangi. Variabel bebas dalam penelitian ini meliputi jenis warna cahaya lampu yang digunakan adalah putih, kuning dan kombinasi keduanya, modifikasi tata letak dan jarak penempatan dilakukan dengan kombinasi sejajar dan zig-zag, modifikasi penempatan dan ketinggian lampu diatur pada jarak 
$7,7.5,8,8.5$, dan 9 meter. Variabel terikat dalam penelitian ini adalah tingkat kenyamanan termal dan visual lapangan indoor bulutangkis meliputi nilai temperatur, kelembaban udara dan intensitas cahaya. Selanjutnya juga dilakukan pengukuran tingkat kenyamanan termal dan visual dengan menggunakan kuesioner pada atlet bulutangkis yang berlatih tanding dengan berbagai variasi yang dilakukan.

Variasi yang dilakukan pengukuran kenyamanan termal dan visual pada titik pengukuran sebagai berikut:

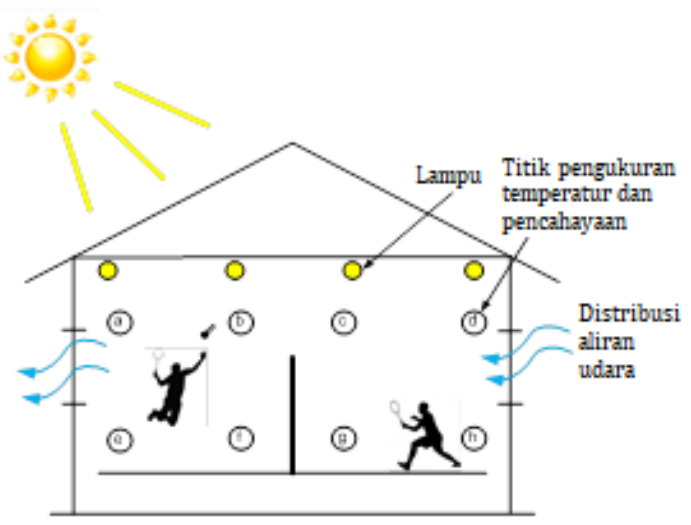

Gambar 4. Skema peralatan penelitian

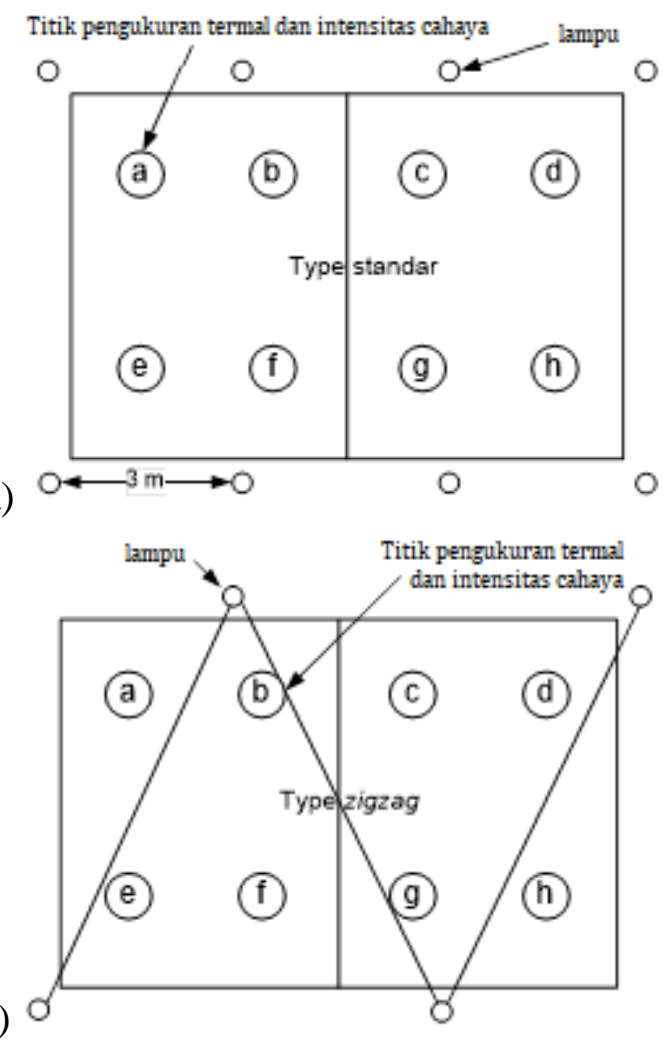

Gambar 5. Pola pengaturan titik lampu

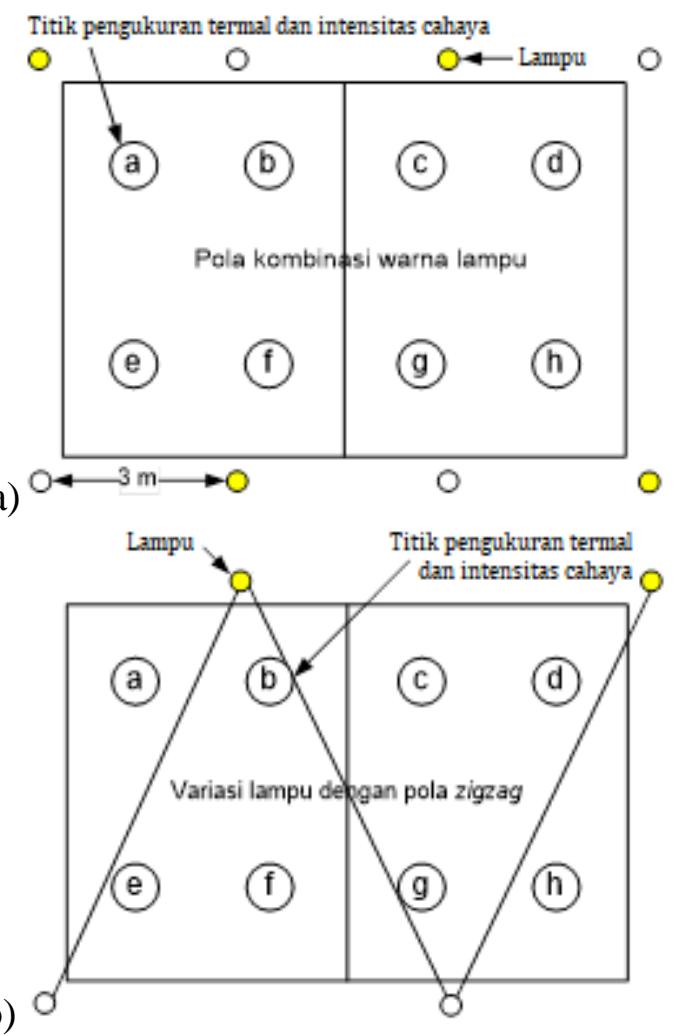

Gambar 6. Pola pengaturan warna dan titik penempatan lampu 


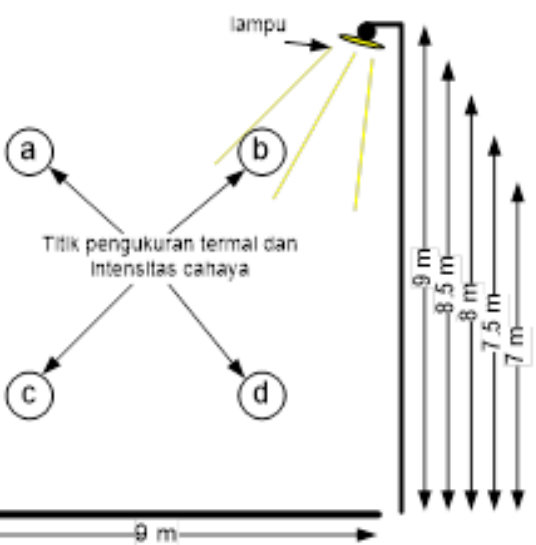

Gambar 7. Model pengaturan jarak ketinggian lampu

\section{HASIL DAN PEMBAHASAN}

Dari hasil analisis didapatkan pada penempatan titik lampu standart (sejajar) dengan pola satu warna semakin rendah posisi lampu memiliki temperature sema- kin tinggi. Pada penempatan titik lampu standart (sejajar) dengan pola warna kombinasi (kuning+ putih) semakin rendah posisi lampu memiliki temperature semakin tinggi. pada penempatan titik lampu zig-zag dengan pola satu warna (putih) semakin rendah posisi lampu memiliki tem-perature semakin tinggi. pada penempatan titik lampu zig-zag dengan pola warna kombinasi (kuning+putih) semakin rendah posisi lampu memiliki temperature sema-kin tinggi.

Tabel 4. Hasil analisis

\begin{tabular}{|c|c|c|c|c|c|c|}
\hline \multirow{3}{*}{$\begin{array}{c}\text { Pola Titik } \\
\text { Pencahayaan }\end{array}$} & \multirow{3}{*}{$\begin{array}{c}\text { Pola Warna } \\
\text { Pencahayaan }\end{array}$} & \multirow{3}{*}{$\begin{array}{c}\text { Jarak } \\
\text { ketinggian } \\
\text { lampu (m) }\end{array}$} & \multicolumn{4}{|c|}{$\begin{array}{c}\text { Indikator Penghawaan } \\
\text { Lingkungan }\end{array}$} \\
\hline & & & \multicolumn{2}{|c|}{ Sebelum } & \multicolumn{2}{|c|}{ Sesudah } \\
\hline & & & $\mathbf{T}_{\mathbf{a}}$ & RH & $\mathbf{T}_{\mathbf{a}}$ & RH \\
\hline \multirow{10}{*}{ Standart (sejajar) } & \multirow{5}{*}{ Satu warna } & 7 & 29.2 & 77.1 & 29.4 & 78.5 \\
\hline & & 7.5 & 29.1 & 77.3 & 29.2 & 78.6 \\
\hline & & 8 & 28.8 & 78 & 29 & 78.8 \\
\hline & & 8.5 & 28.6 & 78.6 & 28.9 & 78.9 \\
\hline & & 9 & 28.5 & 78.9 & 28.8 & 79.3 \\
\hline & \multirow{5}{*}{ Kombinasi } & 7 & 29.4 & 78.7 & 29.9 & 78.9 \\
\hline & & 7.5 & 29.2 & 78.9 & 29.8 & 79 \\
\hline & & 8 & 28.9 & 78.9 & 29.6 & 79 \\
\hline & & 8.5 & 28.6 & 79.1 & 29.1 & 79.4 \\
\hline & & 9 & 28.3 & 79.1 & 28.9 & 79.5 \\
\hline Zig-zag & Satu warna & 7 & 28.8 & 78 & 29.2 & 78.4 \\
\hline
\end{tabular}




\begin{tabular}{|c|c|c|c|c|c|}
\hline & 7.5 & 28.8 & 78.1 & 29 & 78.5 \\
\hline & 8 & 28.7 & 78.5 & 29.1 & 78.9 \\
\hline & 8.5 & 28.6 & 78.8 & 29 & 79.2 \\
\hline & 9 & 28.6 & 79 & 28.9 & 79.6 \\
\hline \multirow{5}{*}{ Kombinasi } & 7 & 28.7 & 78.6 & 29.1 & 78.9 \\
\hline & 7.5 & 28.7 & 78.6 & 29.1 & 78.9 \\
\hline & 8 & 28.6 & 78.6 & 28.8 & 79.1 \\
\hline & 8.5 & 28.4 & 78.8 & 28.8 & 79.1 \\
\hline & 9 & 28.2 & 79 & 28.7 & 79.2 \\
\hline
\end{tabular}

Pada penempatan titik lampu standart (sejajar) dengan pola satu warna (putih) semakin tinggi posisi lampu memiliki kelembaban semakin tinggi. Pada penempatan titik lampu standart (sejajar) dengan pola warna kombinasi (kuning+ putih) semakin tinggi posisi lampu memiliki kelembaban semakin tinggi. Pada penempatan titik lampu zig-zag dengan pola satu warna (putih) semakin tinggi posisi lampu memiliki kelembaban semakin tinggi. Pada penempatan titik lampu zig-zag dengan pola warna kombinasi (kuning+putih) semakin tinggi posisi lampu memiliki kelembaban semakin tinggi. Temperature lingkungan bulutangkis antara $28,2-29,9^{\circ} \mathrm{C}$ dengan kelembaban 77,1-79,6\%. Hal ini mendekati pada suhu nyaman menurut standar tata cara pada gedung olahraga yaitu hangat nyaman $25,8-27,1^{\circ} \mathrm{C}$ ambang atas $31^{\circ} \mathrm{C}$ dengan kelembaban 60\% (Basaria T, 2005).

Intensitas cahaya tertinggi terjadi pada penempatan titik lampu standart (sejajar) dengan pola satu warna (putih) pada ketinggian 7 meter sebesar 843,7 lux. Dan intensitas cahaya terendah pada penempatan titik lampu zig-zag dengan pola warna kom-binasi (kuning+putih) pada ketinggian 9 meter sebesar 382 lux. Hal ini sesuai dengan Standar pencahayaan untuk olahraga bulu-tangkis (indoor) untuk kategori latihan adalah 200 lux dan pertandingan 400 lux (Farid K.M \& Andi R, 2012). Tingkat iluminasi yang dibutuhkan pada lapangan bulutangkis yaitu: 1) 
iluminasi rendah sebe-sar 305 lux, 2) iluminasi sedang sebesar 474 lux, 3) iluminasi tinggi sebesar 595 lux (Animous, 2015).

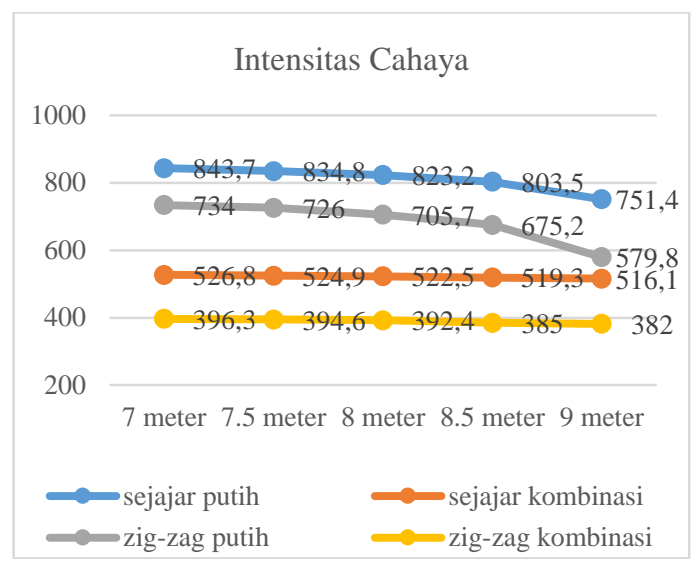

Gambar 8. Grafik Intensitas cahaya

Kenyaman atlet dengan persentase paling tinggi terletak pada penem-patan titik lampu standart (sejajar) dengan pola satu warna (putih) pada ketinggian lampu 8 meter sebesar $81,11 \%$ Sedangkan kenyamanan atlet dengan persentase paling rendah pada penempatan titik lampu zig-zag dengan pola warna kombinai (kuning+putih) pada keting-gian lampu sebesar 42,22\%. Hal ini dikarenakan pada penempatan titik lampu tersebut memiliki temperature dan kelem-baban yang mendekati acuan standar tata cara perencanaan teknis konservasi bangun-an pada gedung olahraga yaitu hangat nyaman
25,8-27, $1^{\circ} \mathrm{C}$ ambang atas $31^{\circ} \mathrm{C}$ dengan kelembaban 60\% (Basaria T, 2005).

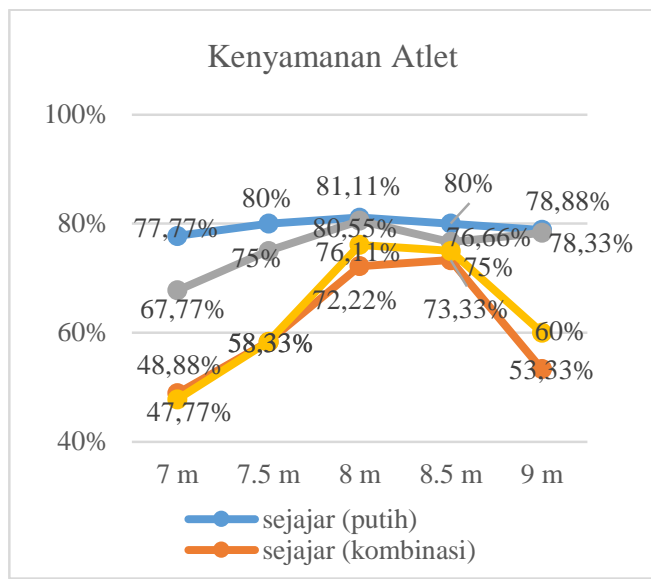

Gambar 9. Grafik kenyamanan atlet

Perubahan kondisi lingkungan lapangan bulutangkis ini terjadi karena dipengaruhi oleh aktifitas fisik. Perubahan temperature dan kelembaban udara lingkungan bulu-tangkis indoor terjadi karena pada saat pertandingan berlangsung terjadi proses pelepasan panas tubuh untuk menjaga agar suhu tubuh berada pada batas yang aman, tubuh harus melepaskan atau membuang kelebihan panasnya melalaui sirkulasi darah dan pengeluaran keringat.

\section{KESIMPULAN}

Hasil penelitian menunjukan bahwa penempatan jarak titik lampu dan kombinasi warna lampu berpengaruh terhadap kondisi lingkungan lapangan indoor bulutangkis. 
Semakin tinggi penempatan titik lampu maka suhu/temperature cenderung semakin kecil. Semakin tinggi penempatan titik lampu kelembaban udara cenderung semakin besar. Semakin tinggi penempatan titik lampu intensitas cahaya cenderung semakin berkurang. Suhu/temperature pola lampu satu warna (putih) cenderung lebih kecil dari pola warna kombinasi (kuning+putih). Kelembaban udara pola lampu satu warna (putih) cenderung lebih kecil dari pola warna kombinasi (kuning+putih). Tingkat kenya-manan atlet terletak pada penempatan titik lampu standart (sejajar) dengan pola satu warna (putih) pada ketinggian lampu 8 meter.

\section{SARAN}

Penggunaan lampu untuk gedung olahraga bulutangkis indoor sebaiknya menggunakan penempatan titik lampu standart (sejajar) dengan pola satu warna (putih) dengan ketinggian 8 meter.

Diadakan penelitian lanjutan dengan menggunakan variasi yang lebih banyak, dilakukan di gedung dengan standar nasional dan pengujian tingkat kenyamanan menggu-nakan atlet nasional.

\section{DAFTAR PUSTAKA}

Agustin Puryani Wulandari. (2010). Pengaruh intensitas cahaya terhadap aktivitas kerja bagian produksi di PT. Indofood CBP Sukses Makmur Divisi Noodle cabang Semarang. Fakultas Kedokteran. Universitas Sebelas Maret.

Basaria Talarosha. (2005). Menciptakan kenyamanan thermal dalam bangunan. Jurnal Sistem Teknik Industri Volume 6, No. 3.

Irfan S. (2007). Pengaruh intensitas cahaya terhadap kinerja atlet billiard. Yogyakarta: Fakultas Psikologi dan Ilmu Sosial Budaya Universitas Islam Indonesia.

Farid K.M. \& Andi R. (2012). Desain pencahayaan lapangan bulutangkis indoor ITS. Jurnal Teknik POMITS Vol.1 No.1 Hal 1-8.Nurul Sawitri Vanani. (2008). Gambaran tekanan panas dan keluhan subyektif pada pekerja di bagian curing PT. Multistrada Arah Sarana Tbk. tahun 2008. Jakarta: Fakultas Kesehatan Masyarakat, Universitas Indonesia.

SNI 03-3647. (1994). Tata cara perencanaan teknik bangunan gedung olahraga. Bandung: Departemen Pekerjaan Umum, Yayasan LPMB.

SNI 16-7063. (2004). Nilai ambang batas iklim kerja (panas), kebisingan, getaran tangan-lengan dan radiasi sinar ultra ungu di tempat kerja. ICS 13.100. Badan Standardisasi Nasional. 
Jurnal Olahraga Prestasi, Volume 13, Nomor 2, Juli 2017 | 138 